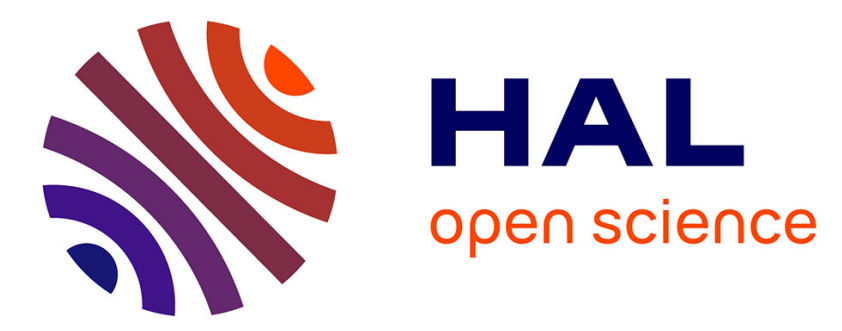

\title{
Finite element simulation of the Portevin-Le Chatelier effect in highly reinforced metal matrix composites
}

\author{
Matthieu Maziere, Andreas Mortensen, Samuel Forest
}

\section{To cite this version:}

Matthieu Maziere, Andreas Mortensen, Samuel Forest. Finite element simulation of the Portevin-Le Chatelier effect in highly reinforced metal matrix composites. Philosophical Magazine, 2021, 101 (12), pp.1471-1489. 10.1080/14786435.2021.1919331 . hal-03372373

\section{HAL Id: hal-03372373 \\ https://hal.science/hal-03372373}

Submitted on 16 Oct 2021

HAL is a multi-disciplinary open access archive for the deposit and dissemination of scientific research documents, whether they are published or not. The documents may come from teaching and research institutions in France or abroad, or from public or private research centers.
L'archive ouverte pluridisciplinaire HAL, est destinée au dépôt et à la diffusion de documents scientifiques de niveau recherche, publiés ou non, émanant des établissements d'enseignement et de recherche français ou étrangers, des laboratoires publics ou privés. 


\section{Finite element simulation of the Portevin-Le Chatelier effect in highly reinforced metal matrix composites}

\section{Matthieu Maziere, Andreas Mortensen \& Samuel Forest}

To cite this article: Matthieu Maziere, Andreas Mortensen \& Samuel Forest (2021): Finite element simulation of the Portevin-Le Chatelier effect in highly reinforced metal matrix composites, Philosophical Magazine, DOI: 10.1080/14786435.2021.1919331

To link to this article: https://doi.org/10.1080/14786435.2021.1919331

View supplementary material $₫$

\section{Published online: 05 May 2021.}

Submit your article to this journal

Q View related articles ¿

View Crossmark data $\nearrow$ 


\title{
Finite element simulation of the Portevin-Le Chatelier effect in highly reinforced metal matrix composites
}

\author{
Matthieu Maziere ${ }^{\mathrm{a}}$, Andreas Mortensen ${ }^{\mathrm{b}}$ and Samuel Forest ${ }^{\mathrm{a}}$ \\ ${ }^{a}$ MINES ParisTech, PSL Research University, MAT- Centre des matériaux, CNRS UMR 7633, Evry, France; \\ ${ }^{b}$ EPFL (Ecole Polytechnique Fédérale de Lausanne), LMM, Lausanne, Switzerland
}

\begin{abstract}
The Portevin-Le Chatelier effect in an $\mathrm{AlCu} / \mathrm{Al}_{2} \mathrm{O}_{3}$ composite with a large volume fraction $(60 \%)$ of ceramic particles is investigated from a numerical point of view using a strainageing visco-plastic material model for the metallic matrix and several different finite element meshes based on real microstructures. Even for this very large volume fraction, some serrations are observed on the experimental tensile stress/strain curves, together with the propagation of bands of localised plasticity. The finite element model succeeds in reproducing the serrations and the propagation of bands experimentally observed, and allows a fine analysis of the spatio-temporal evolution of the bands of localised plastic strain rate. Different volume fractions are then virtually generated, tested, and compared to outline the influence of this second phase on the Portevin-Le Chatelier effect.
\end{abstract}

\section{ARTICLE HISTORY}

Received 3 February 2020

Accepted 21 December 2020

\section{KEYWORDS}

Portevin-Le Chatelier effect; metal matrix composite; dynamic strain ageing; statistical analysis

\section{Introduction}

Many metallic materials exhibit serrations on their global tensile stress/strain curves within a given range of temperature and deformation rate [1]. This so-called Portevin-Le Chatelier (PLC) effect is due to the interaction between mobile dislocations and solute atom diffusion, and is a manifestation of dynamic strain ageing [2]. Strain ageing can induce a negative strain rate sensitivity in a given range of temperature and deformation rate. This negative sensitivity, in turn, leads to a strain localisation phenomenon characterised by bands of high plastic strain rate propagating in tensile specimens, and by serrations appearing on the global stress/strain curve. The PLC effect has been investigated in many aluminium alloys, from the early observations of Portevin and Le Chatelier [3] to more recent works using advanced experimental methods such as digital image correlation [4,5], digital image thermography [6], or $\mathrm{X}$-ray laminography associated with 3D digital image correlation [7]. The 
effect has been reported in some aluminium alloys of the AA2xxx family [8-11], the AA5xxx family [12-15] and the AA6xxx family [16].

The PLC effect has also been observed in aluminium-ceramic composites with a low [12,13], intermediate [17] or high [18, 19] volume fraction of reinforcement. The first group of composites, of ceramic particle volume fraction between $2 \%$ and $5 \%$, were designed in order to postpone the occurrence of the PLC effect by disrupting dislocation avalanches. The second group, with a volume fraction up to $60 \%$, was designed to obtain a high stiffness coupled with strength/toughness combinations similar to high-strength engineering $\mathrm{Al}$ alloys, using a standard Al-Cu matrix. In both cases, it was found that the PLC effect is not suppressed and that serrations occur in general for an even lower strain level. The influence of the volume fraction of particles on the shape of the serrations has been investigated in $[20,21]$ using statistical analysis of stress drops and multi-fractal analysis. Propagative visco-plastic instabilities in multi-phase metallic alloys, such as PLC-like serrations and associated localisation bands, have been recently observed in some third-generation highstrength TRIP/TWIP steels [22-25] where plastic instabilities initiate and propagate only in one of the phases. In this case, the volume fraction of each phase (ferrite and austenite/martensite) is close to $50 \%$ and the contrast between their mechanical properties is smaller than in aluminium/ceramic composites.

The influence of a second phase on the occurrence and evolution of the PLC effect was already investigated earlier from a theoretical $[26,27]$ and from an experimental point of view $[28,29]$. The size and number of precipitates in Aluminium alloys seem to influence the critical strain i.e. the strain for which the PLC effect starts to occur. The kinetics of strain propagating bands - width and velocity - are also affected by this second phase.

Strain ageing inhomogeneous materials can be described using an elastovisco-plastic model which reproduces the negative strain rate sensitivity, such as the KEMC model proposed by Kubin, Estrin, and McCormick [30, 31]. The KEMC model can predict serrated yielding and propagative plastic bands during the finite element simulation of tensile specimens [32]. This approach has been applied to many industrial alloys, including nickel-based superalloys [33]. The model has been parametrised for the room temperature behaviour of the AA5083 alloy [14], the AA2024 alloy [8], and the AA5754 alloy $[15,34]$ and used for the finite element simulation of the PLC effect in smooth or notched 3D specimens. The predictive power of the KEMC model was recently demonstrated in the case of complex loading conditions including strain rate jumps and relaxations tests in a AA2139 alloy [10], and for the simulation of forming processes [35].

The KEMC model has also been used to simulate the PLC effect in heterogeneous materials, such as polycrystals, by translating the constitutive equations at the grain level [36-38]. The case of metal-matrix composites has been addressed in $[12,13]$ for an AA5754 aluminium matrix and a 
low volume fraction of ceramic particles ( $2 \%$ and $5 \%)$. The ceramic particles were accounted for by Graff et al. [13] using full-field 2D plane stress simulations of periodic idealised microstructures. The simulation results show that the hard elastic second phase does not represent an obstacle strong enough to cancel serrations in the stress/strain curve or the associated propagating localisation bands of plasticity. The introduction of particles seems, however, to decrease the amplitude of the serrations and the critical strain for which they occur [13]. The actual shape of the particles was not accounted for in this work since they were always assumed to be perfectly circular. Furthermore, only low volume fractions of ceramics were investigated ( $2 \%$ and $5 \%$ ), while it appears that PLC effects in $\mathrm{Al}-\mathrm{Al}_{2} \mathrm{O}_{3}$ composites can also occur for a very large volume fraction of ceramic particles, up to $60 \%$ [18]. Finally, the analysis of serrations gave no statistical analysis of the type performed in [21].

The aim of the present work is to show that the KEMC model can effectively simulate the PLC effect observed in metal-matrix composites, even with a large volume fraction of reinforcement, of up to $60 \%$. For that purpose $2 \mathrm{D}$ planestress finite element simulations have been carried out using meshes based on the real composite microstructure [39]. The influence of the prescribed strain rate and of the ceramic volume fraction is investigated, and statistical analysis of the serrations is carried out for three different ceramic volume fractions $(0 \%, 30 \%$, and $60 \%)$. The material and finite element model are presented in Section 2. In Section 3, the simulations on the $60 \%$ volume fraction composite are detailed. In Section 4, the influence of the volume fraction is investigated, and a statistical analysis of serrations is proposed. Finally, in Section 5, the main results are summarised.

\section{Material and model}

\subsection{Material}

Ceramic reinforced metals can be produced up to a rather high particle volume fraction (i.e. 60\%) using infiltration processing. The mechanical properties of such composites have been investigated extensively in the literature $[18,19,39-41]$. In these studies, several different composites were manufactured, changing the size, the shape, and the volume fraction of the ceramic particles, and the composition of the metallic matrix. In the present study, composites made of an Al-2 or 4.5 wt. pct. $\mathrm{Cu}$ matrix and $60 \%$ by volume of polygonal $\mathrm{Al}_{2} \mathrm{O}_{3}$ particles with an average size of $25 \mu \mathrm{m}$, are used as a starting point for the simulations. Room-temperature tensile curves of this material were provided in Figure 2 of [18]. They exhibit large serrations typical of the PLC effect. In spite of their high volume fraction of ceramic particles, those composites also display propagating bands of deformation 


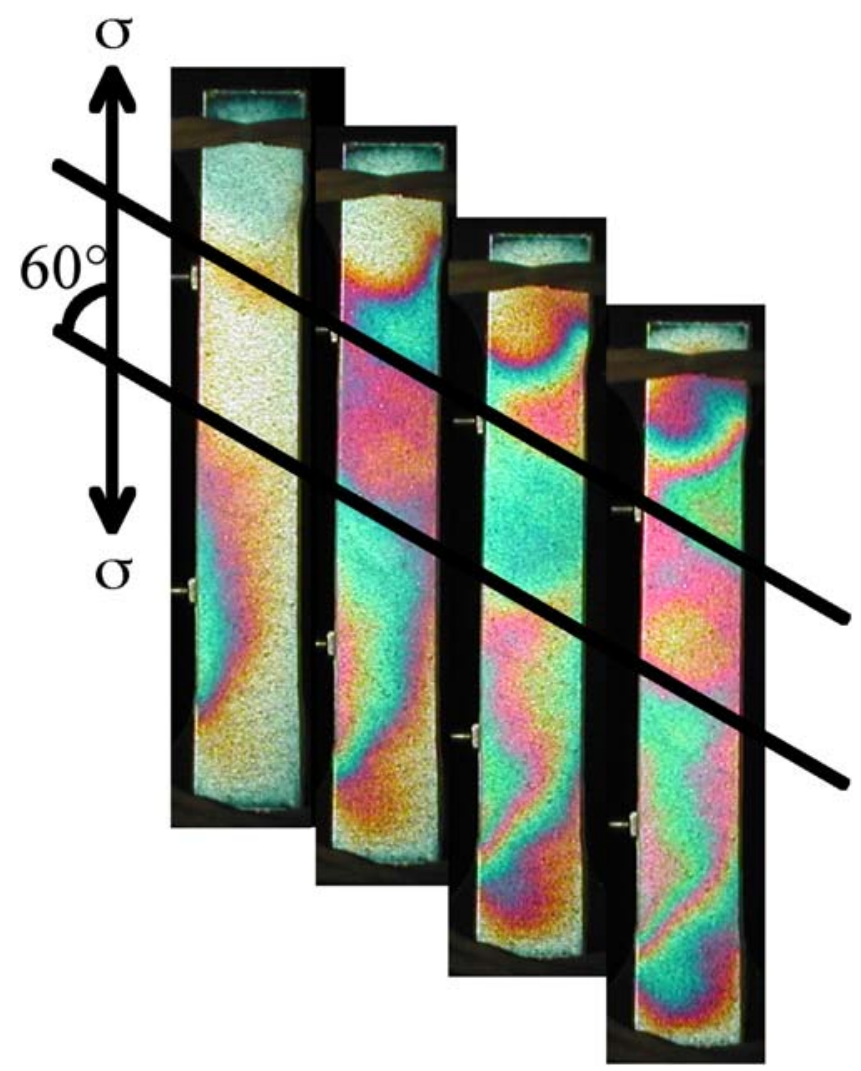

Figure 1. Propagation of a PLC band in a tensile specimen of Al-2 wt. pct. Cu in the T4 condition reinforced with 60 vol. pct. $\mathrm{Al}_{2} \mathrm{O}_{3}$ particles, observed using photoelastic measurements of the strain distribution, showing the propagation of a deformation band characteristic of the PLC effect. Sample width normal to the (vertical) tensile axis was $6 \mathrm{~mm}$; the strain rate was $10^{-4}$ $\mathrm{s}^{-1}$. Frames (from left to right) were taken ten seconds apart, at (average gage-section) strain values of $0.4 \%, 0.5 \%, 0.6 \%$ and $0.7 \%$, respectively.

characteristic of the PLC effect in homogeneous materials. This can be seen in Figure 1, which was produced using Photostress $@$ instrumentation and accessories (photoelastic coating and adhesive), purchased from Measurements Group, Inc. (Raleigh, NC, USA), to visualise the propagation, the orientation and the intensity of the strain field along the flat gage section surface of a tensile sample while it is deformed. Briefly, the method uses photoelastic properties of the adhesive coating, the index of refraction of which is a function of strain allowing to visualise the strain field when observed with polarised light.

The corresponding tensile curve of the matrix material in these composites is not known a priori, because the particles alter its microstructure and plastic deformation behaviour, see e.g.[42, 43]. As a first approximation, therefore, we assimilate the matrix of these composites to the copper-containing AA2024 alloy, KEMC model parameters of which are given in [8]. 

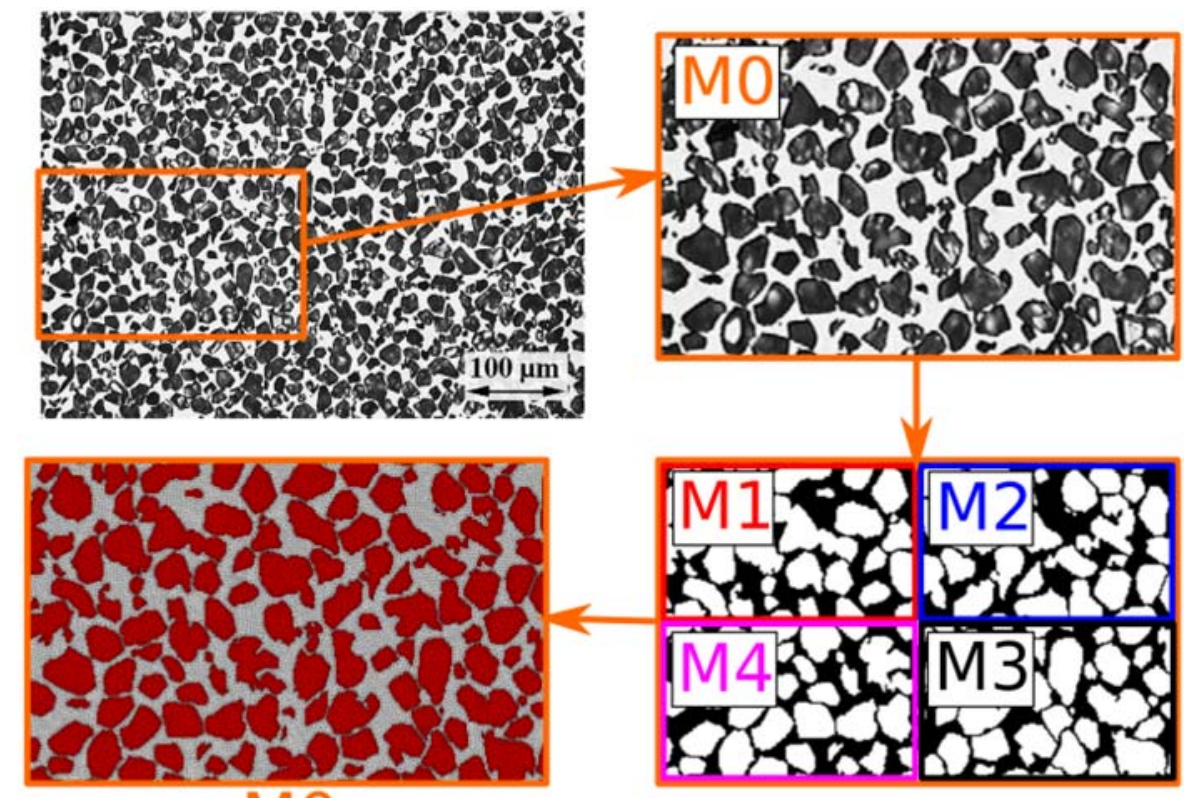

\section{$\mathrm{MO}$}

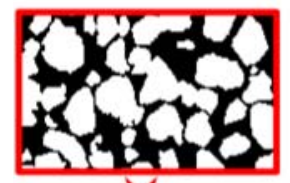

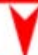

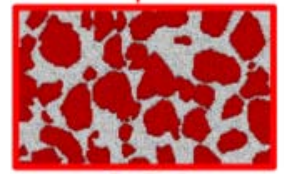

M1
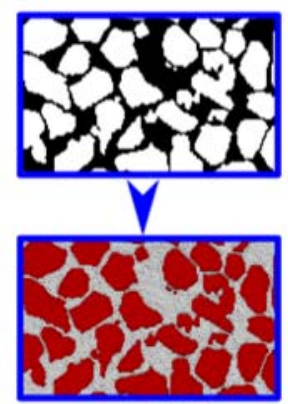

M2
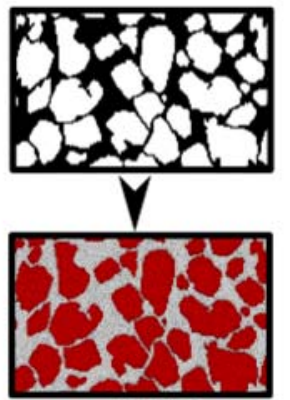

M3
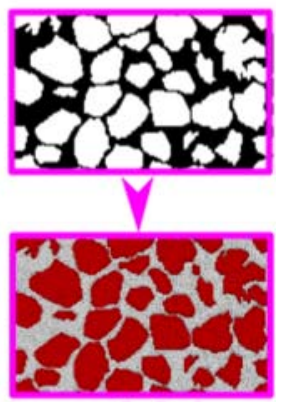

M4

Figure 2. Meshing process of five different parts of the micro-structure. A $320 \mathrm{~m} \times 200 \mathrm{~m}$ portion of the microscopic image is binarised and then meshed in 2D. This portion was also divided in four $160 \mathrm{~m} \times 100 \mathrm{~m}$ sub-pictures that are meshed separately for simulation comparisons.

\subsection{Finite element model}

In the previous numerical study on the PLC effect in metal matrix composite by Graff et al. [13], the finite element model was based on a periodic elementary cell including one single circular particle. Some simulations were also carried out on 'representative' volumes containing 8 or 18 randomly distributed circular particles; however, their real shape was not accounted for. In the present study, the model is based on the actual microstructure of the real material observed along a polished cross-section through scanning electron microscopy as presented in [39] and in Figure 2 of the present work. 
The selection and meshing process of a representative elementary volume, presented in Figure 2, can be divided into three main steps:

(1) A portion of the cross-section of the composite, of dimensions $320 \mathrm{~m} \times 200 \mathrm{~m}$, is extracted from the original picture.

(2) This picture is binarised with the matrix in black and the ceramic particles in white.

(3) The binarised picture is meshed using 6-node triangular elements with reduced integration. The technique ensures conformal meshing of the matrix-inclusion interfaces.

In order to check the representative character of the considered surfaces, the binarised picture of Step (2) was also divided into four different sub-pictures whose size represents $160 \mathrm{~m} \times 100 \mathrm{~m}$ of material, each of them being then meshed separately. The large mesh is denoted $M 0$ in the following, while the four smaller ones are called, respectively, $M 1, M 2, M 3$, and $M 4$.

It must also be noted that between Steps (2) and (3), the size of particles can be artificially decreased using the erosion image analysis technique. Removing successively one row of pixels along the border of each particle allows to generate virtual composites and the corresponding meshes with volume fractions of around $60 \%$ (no erosion), 50\%, 40\%, 30\%, 20\%, 10\% or $0 \%$ (full erosion). This method has been used in the present work based on Sub-picture M3. The different meshes with variable volume fractions are used for the investigation presented in Section 4.

For all simulations presented in the following, the boundary conditions are such that tensile loading is applied along the length dimension (horizontally in Figure 2), while the lateral lines are left free of force. All the meshes used in the present work are 2D. The finite element simulations that are presented in the following are carried out using a plane stress assumption. This is probably unrealistic compared with the real specimen response that is presented on Figure 1, except of course along its outer skin. Some simulations using a 3D extruded mesh with two elements in the thickness have also been carried out. They are not presented here but reveal that the results in terms of serration analysis are qualitatively not affected by choice of a 2D plane stress model. A more accurate description of the full 3D micro-structure could give some different results; however, in this case, the computation time would increase drastically. Finally, the mesh size influence has also been tested using three different element sizes and no significant difference was observed between these simulations.

Perfect bonding between matrix and particles is assumed in the finite element simulations. This means that the displacement vector is continuous at the interface: no crack and no sliding. In addition, the traction vector is also continuous (in the weak sense of the finite element method) so that forces are transmitted at the interfaces. Note that the plastic strain tensor 
and its rate are discontinuous at the interface since these internal variables are not subjected to spatial continuity requirements. The ensuing discontinuity across the interface has the implication that alterations in matrix hardening caused by the additional dislocations that are required to satisfy this discontinuity [44] (be they interfacial Kröner dislocations situated along the interface or geometrically necessary dislocations distributed within the matrix), or in other words the plasticity size effect, known to be manifest in metal matrix composite materials in general [45] and those modelled here in particular [42], is neglected in what follows. This assumption finds partial justification here in the fact that the plasticity size effect is known to be far smaller in composites that have an alloyed, as opposed to a pure metal, matrix. These ideal conditions are questionable, especially in the case of high particle volume fractions, but represent a reasonable first approximation. Interesting future work could concentrate on measuring high-resolution strain fields along the particle/matrix interface (by DIC for instance) to observe possible discontinuities of the displacement field at the interfaces. Cohesive zone models could then be applied to account for specific interface laws. Another possible extension of interface conditions would be to enforce continuity requirement on the tangent part of the stress tensor as suggested by $[44,46]$ on the basis of conservation of the continuum Burgers vector across the interface.

\subsection{Constitutive equations}

The mechanical model used in this work for the matrix was mainly introduced by McCormick [31] and modified in the following work [47, 48]. The formulation used here was proposed in [8] where the model was successfully identified for the Al-Cu alloy AA2024.

The strain rate tensor $\dot{\varepsilon}$ is split into elastic and plastic contributions:

$$
\begin{gathered}
\underset{\sim}{\dot{\varepsilon}}=\underset{\sim e}{\dot{\varepsilon}}+\underset{\sim p}{\dot{\varepsilon}} \\
\underset{\sim}{\sigma}=\underset{\sim}{E}: \underset{\sim e}{\boldsymbol{\varepsilon}_{e}}
\end{gathered}
$$

where $\underset{\approx}{E}$ is the fourth rank tensor of elastic moduli. The evolution of the plastic part is provided by the yield function and the plastic flow rule:

$$
\begin{gathered}
f\left(\underset{\sim}{\boldsymbol{\sigma}}, p, t_{a}\right)=\sigma_{e q}(\underset{\sim}{\boldsymbol{\sigma}})-R(p)-R_{a}\left(p, t_{a}\right) \\
\underset{\sim p}{\dot{\varepsilon}}=\underset{\sim}{\boldsymbol{n}} \\
\underset{\sim}{\boldsymbol{n}}=\frac{\partial f}{\partial \underset{\sim}{\boldsymbol{\sigma}}}
\end{gathered}
$$


where $p$ is the accumulated plastic strain, $t_{a}$ the ageing time, and $\sigma_{e q}$ the von Mises equivalent stress measure. $R(p)$ is the isotropic strain hardening function, taken here as

$$
R(p)=R_{0}+Q(1-\exp (-b p))
$$

where $R_{0}, Q$ and $b$ are material parameters. The accumulated plastic strain rate $\dot{p}$ is computed using the Norton visco-plastic flow rule:

$$
\dot{p}=\left(\frac{\langle f\rangle}{K}\right)^{m}, \quad\langle f\rangle=\max (0, f)
$$

The age-hardening variable $R_{a}$, related to dynamic strain ageing, is calculated from the over-concentration $C_{s}$ of solute atoms around dislocations. $C_{s}$ is a function of both internal variables of the model, the accumulated plastic strain $p$ and the ageing time $t_{a}$. The ageing time increment is computed from an evolution law in which the accumulated plastic strain rate $\dot{p}$ intervenes:

$$
\begin{gathered}
R_{a}\left(t_{a}\right)=P_{1} C_{s}\left(t_{a}\right)=P_{1} C_{m}(p)\left[1-\exp \left(-\left(\frac{t_{a}}{t_{0}}\right)^{n}\right)\right] \\
\dot{t}_{a}=1-\frac{t_{a}}{t_{w}} ; \quad t_{w}=\frac{w(p)}{\dot{p}}
\end{gathered}
$$

where $P_{1}, t_{0}, n$ are three material parameters controlling the strain ageing contribution to the flow stress. In the model of [8], the parameters $w$ and $C_{m}$ are linear functions of the accumulated plastic strain, such that a coupling exists between strain hardening and strain ageing:

$$
\begin{gathered}
C_{m}(p)=C_{m 1}+C_{m 2} p \\
w(p)=w_{1}+w_{2} p
\end{gathered}
$$

All the parameters of the model for the constitutive behaviour of AA2024 aluminium alloy at room temperature are given in [8]. They have been used without any modification in the present work. Here, again the choice of an isotropic elasto-visco-plastic model to describe the metallic matrix behaviour can be discussed. Indeed, the width of the channels between ceramic particles varies from $\sim 50 \mu \mathrm{m}$ to less than $1 \mu \mathrm{m}$. The number of grains in each channel should in all rigour be at least 10 for the model to apply, which is clearly not the case here. A crystal plasticity model allowing for an accurate description of the local grain anisotropy and orientation would be more appropriate to predict the kinetics of overall propagating bands as done in [49] for a titanium alloy. Qualitatively the results should, however, not be very different, at least for the global stress/strain curves. 
Finally, the material behaviour used for the alumina ceramic phase is isotropic linear elastic with Young's modulus of $370 \mathrm{GPa}$ and a Poisson ratio of 0.22 , as in [13].

All simulations presented in this work have been carried out using the Zset finite element program. This is an implicit finite element software devoted to non-linear quasi-static simulations of continuum mechanics problems [50, 51]. The constitutive and balance equations are solved by implicit Newton methods making use of the consistent tangent matrix. Automatic time-stepping control is used in order to avoid divergences during the simulation. More details on the numerical process used for the finite element simulation of the Portevin-Le Chatelier effect are available in the following article [32].

\section{Large volume fraction material ( $60 \%$ ceramic particles)}

Five different simulations have been carried out using Meshes $M 0, M 1, M 2, M 3$, and $M 4$ of Figure 2 and the constitutive equations given in the previous section. The global prescribed strain rate is equal to $10^{-2} \mathrm{~s}^{-1}$ with a goal to obtain Atype bands characterised by a regular and repetitive propagation in the specimen [32]. The global stress/strain curves resulting from these five simulations are given in Figure 3. For a better view, the curves are vertically shifted by 20 $\mathrm{MPa}$. Portevin-Le Chatelier serrations are observed on all the curves. They occur more or less for the same strain level, i.e. around $1 \%$ of global deformation. The shape (amplitude, frequency) of the serration also looks very similar between the five curves; however, a more quantitative statistical analysis should be carried out to confirm this.

A special focus is then put on the simulations carried out on the larger mesh denoted M0. In particular, the spatio-temporal evolution of the deformation is

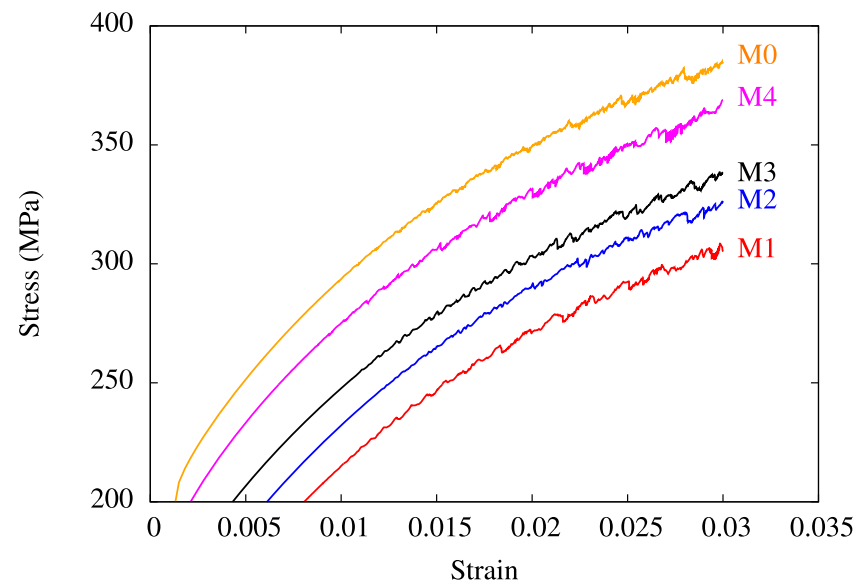

Figure 3. Influence of the original picture and mesh on the global stress-strain curve provided by the finite element simulations. For a better view, the curve are vertically shifted by $20 \mathrm{MPa}$. M0: -40 MPa, M4: -20 MPa, M3: noshift, M2: +20 MPa, M1: +40 MPa. 


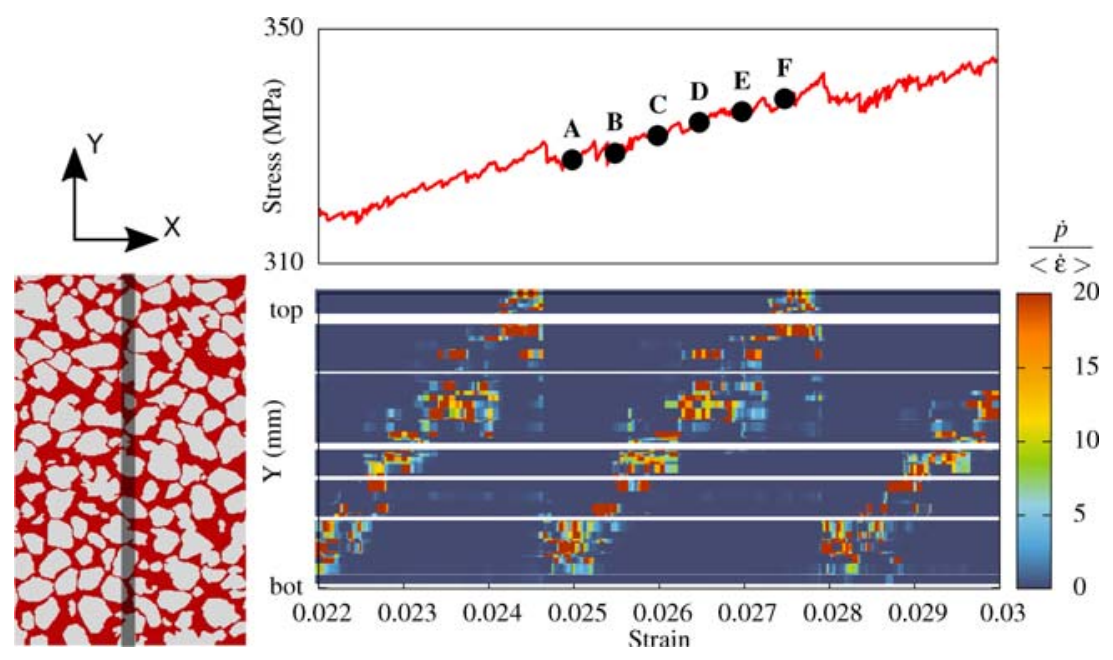

Figure 4. Spatio-temporal evolution of the plastic strain rate as a function of time and position along the $Y$-axis for the large mesh $(M 0)$ simulation. The selected area for the analysis is outlined in grey on the binarised image on the left of the picture. The corresponding global sample stress/strain evolution for the investigated strain range is also given at the top.

investigated for the last part of the simulation, i.e. between $2 \%$ and $3 \%$ of global strain. The spatio-temporal patterns plotted in Figure 4 present in a simple way the position and the intensity of the bands as a function of time. This representation has been used experimentally to characterise the kinetics of PLC bands in aluminium alloys based on optical measurements in [52], digital image thermography [53] or digital image correlation measurements [4]. Only a part of the specimen is accounted for in plotting this type of pattern, namely one vertical strip of width $10 \mu \mathrm{m}$, as presented on the left-hand part of Figure 4 . For each time step of the simulation, the value of the accumulated plastic strain rate $\dot{p}$ is computed at all integration points located inside the selected dark-grey area oriented along the $Y$ tensile axis, and projected along a single $Y$-line in order to plot the spatio-temporal pattern. The corresponding global stress/ strain evolution is also presented here in order to relate the band position with the serrations. It is observed that the main strain rate localisation band forms and globally propagates from one side of the sample surface to the other. A stress peak is observed when a band reaches one side of the surface. The local plastic strain rate can be larger than 20 times the global prescribed strain rate, i.e. $10^{-2} \mathrm{~s}^{-1}$. The white strips observed for some $Y$ values in the spatio-temporal pattern are due to the presence in the strip of ceramic particles, and consequently to the lack of any integration point for these particular $Y$ coordinates.

Plastic strain rate $\dot{p}$ maps are plotted on Figure 5 for six different steps of the simulation defined on the top of Figure 4 and denoted A, B, C, D, E, F. These six steps correspond to the propagation of the band from one side of the surface 


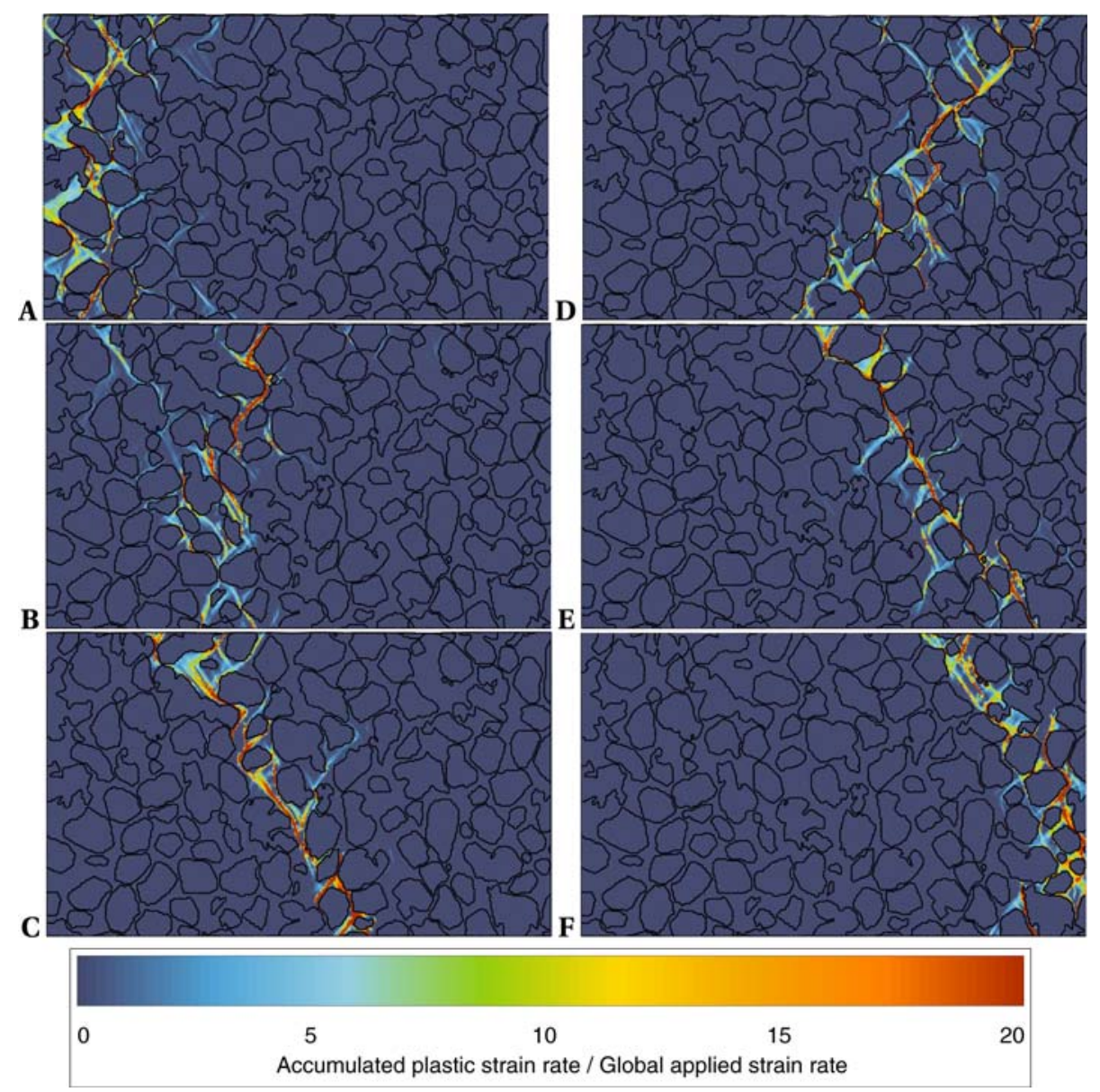

Figure 5. Map of the plastic strain rate $\dot{p}$ in the investigated area for the large mesh (M0) simulation for six different steps plotted on the stress/strain curve of Figure 4. The tensile direction is horizontal. The plastic strain rate band propagates from one side of the area to the other, experiencing some temporary arrests and orientation changes.

to the other side. It appears that the main band is inclined with respect to the tensile axis by an angle varying between $50^{\circ}$ and $60^{\circ}$, which is close to the theoretical value for strain localisation under tension $\left(54.73^{\circ}\right.$, see [54]), and also in agreement with the experimental data in Figure 1. As seen, the ceramic particles do not prevent the global formation and propagation of the band, even if it can be temporarily arrested. The particles can however induce an increase in the band width, as in Picture 5 (B), and may enforce a change in the band orientation, as between pictures (C) and (D) or (D) and (E). The propagation of the band in the composite is less regular than for the corresponding homogeneous material [8]. It is not fully obvious whether the propagation is of $\mathrm{A}$ of B type in the present simulation. Locally, the band can propagates by moving smoothly or jumping using channels between particles. The full 
animation of the M0 simulation is available in the supplementary material associated with this article.

The influence of the global prescribed strain rate has also been investigated for this large volume fraction of ceramic using the reduced M3 mesh. The corresponding stress/strain curves are plotted in Figure 6 for five different strain rates, namely $10^{-1}, 10^{-2}, 10^{-3}, 10^{-4}, 10^{-5} \mathrm{~s}^{-1}$. The curves are in this case not shifted and a negative strain rate sensitivity is clearly visible. Some usual features of the PLC effect in metallic alloys without ceramic inclusions are also retrieved. The critical strain for which the serrations occur describes a Ucurve with respect to strain rate, i.e. it decreases and then increases while the strain rate increases. For low strain rates $\left(10^{-4}, 10^{-5} \mathrm{~s}^{-1}\right)$, the serrations appears to be of C-type with a large amplitude and frequency, while for large strain rates $\left(10^{-1}, 10^{-2} \mathrm{~s}^{-1}\right)$, the A-type is observed. The spatio-temporal propagation of the bands for these different strain rates is not presented here but is in agreement with the serration type observed on the stress/strain curve: randomly nucleated bands are observed at low strain rates, in contrast to regular and side-to-side propagating bands for high strain rates.

\section{Influence of volume fraction}

The influence of the ceramic particle volume fraction is investigated in this section using the virtual micro-structures generated using the erosion method presented in Section 2.2. The reference simulation based on the M3 mesh is compared with six simulations carried out under the same boundary conditions and prescribed strain rate $\left(10^{-2} \mathrm{~s}^{-1}\right)$ for ceramic volume fractions of $50 \%, 40 \%, 30 \%, 20 \%, 10 \%$ and $0 \%$. The corresponding stress/strain curves

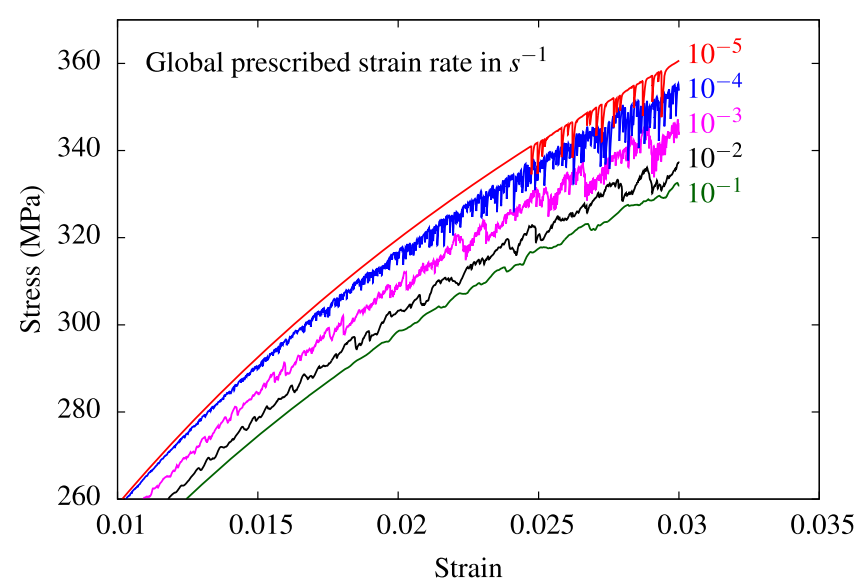

Figure 6. Influence of prescribed strain rate on the simulated stress/strain curves for the small mesh M3. A negative strain rate sensitivity is observed and the influence of strain rate on the critical strain and the serration shape is similar to what is usually observed for a single-phase material. 


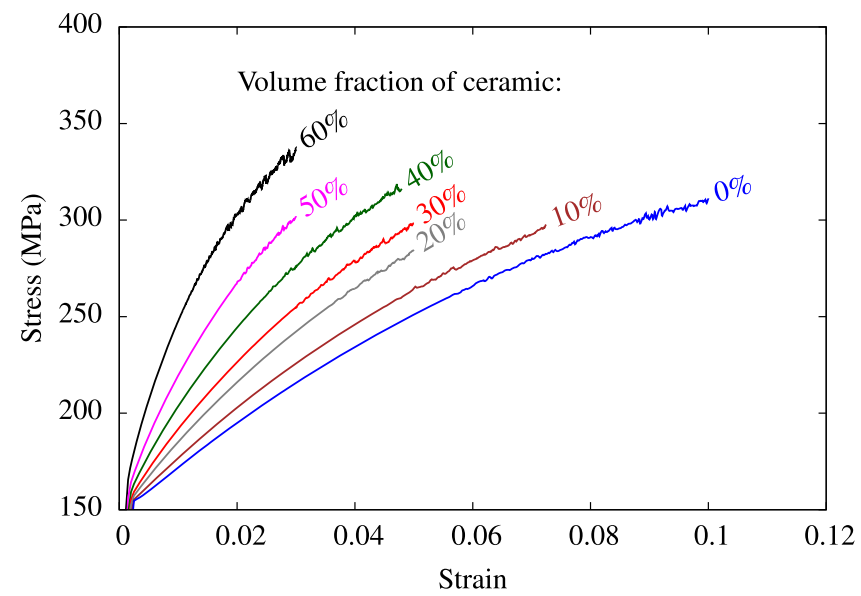

Figure 7. Influence of ceramic volume fraction on the simulated stress/strain curve. The meshes for the various volume fractions are generated using an erosion method on the binarised $M 3$ image. The hardening rate and the critical strain are affected by the particle volume fraction, but the critical stress seems to be almost constant.

are plotted in Figure 7 for the seven investigated volume fractions. Because of the influence of the purely elastic response of the ceramic phase, the apparent hardening rate increases with the particle volume fraction, as expected. Portevin-Le Chatelier serrations are observed for all simulations. The critical strain for the occurrence of serrations decreases with an increase in the particle volume fraction, while the corresponding critical composite stress seems to be roughly always the same, i.e. around $270 \pm 10 \mathrm{MPa}$.

We also note that if one divides the strain at which the PLC effect appears in each of the seven composite curves in Figure 7 by the volume fraction metal (which varies from $100 \%$ to $40 \%$ ), one finds that the resulting ratio decreases as the volume fraction particles increases. This implies that the PLC effect appears at an average tensile plastic strain along the sample straining direction that decreases as the particle volume fraction increases. This too is most likely a manifestation of the highly heterogeneous strain state of the matrix in these composites. At a simplistic but perhaps not so unrealistic level of interpretation, this might indicate that the PLC effect is triggered, in these particulate composites, within bands of matrix that extend across the composite roughly normal to the direction of applied stress (see the video as a supplementary material). Given the composite microstructure (discrete ceramic particles in a continuous matrix) such bands exist, and those are indeed regions where (i) the average shear stress borne by the matrix is highest (given that the particles carry an over proportional portion of the stress) and (ii) the high plastic strain rate associated with propagating PLC bands is located, see Figure 5.

The shape of the serrations seems to be affected by the particle volume fraction. A statistical analysis of the serrations is proposed in the following for three different volume fractions: $0 \%, 30 \%$, and $60 \%$ (reference simulation). For that 
purpose, the method proposed in [21] is applied to the simulation results. In that article, a statistical analysis of stress drops was carried out based on tensile experiments on a $\mathrm{AlMg} / \mathrm{Al}_{2} \mathrm{O}_{3}$ metal matrix composite. Three different volume fractions were investigated in that work: $0 \%, 2 \%$, and $5 \%$. The authors show that the number of large drops decreases and the number of small drops increases when the volume fraction of particle is increased.
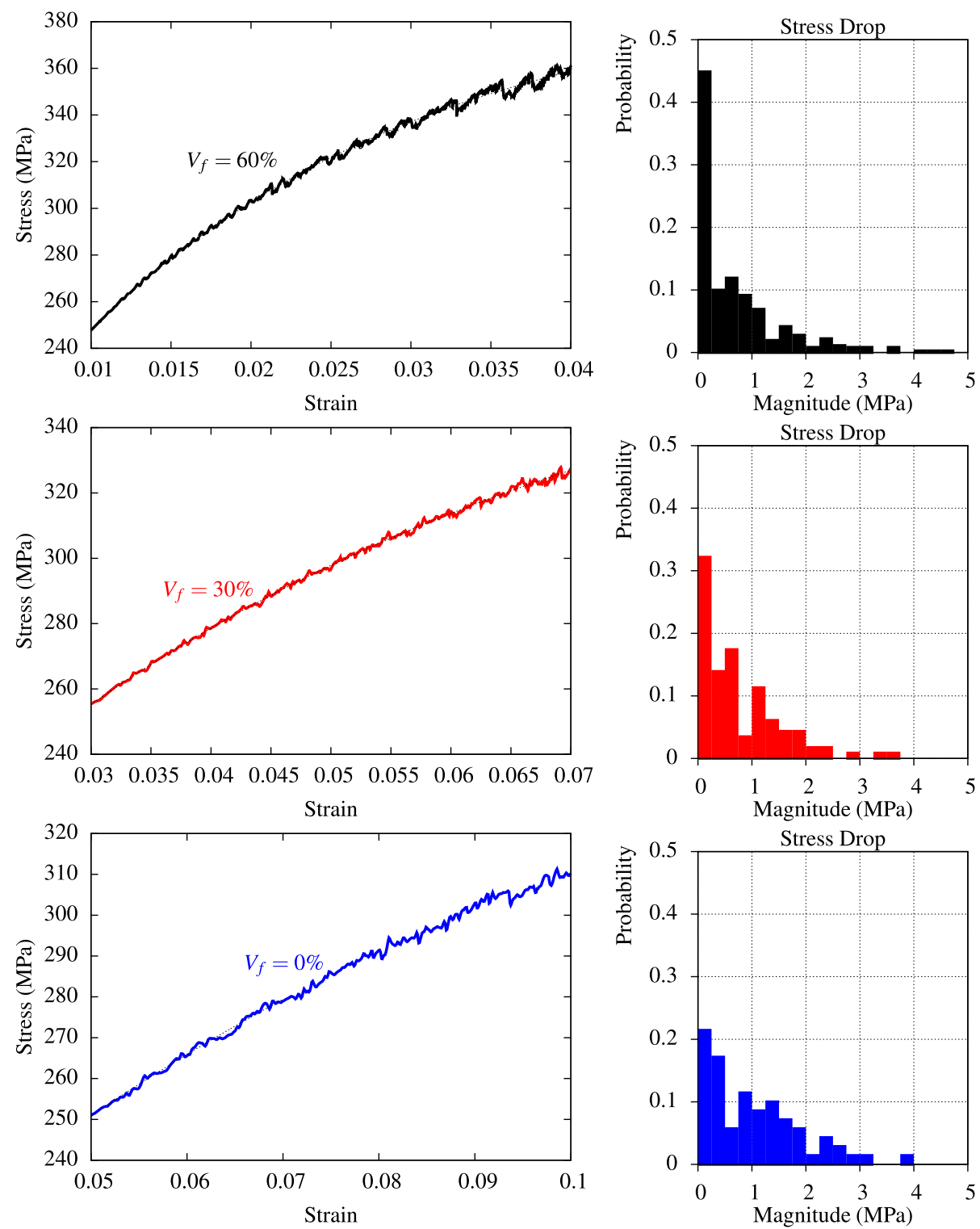

Figure 8. Stress drop statistical analysis based on the simulated stress/strain curves of Figure 7 for three different volume fractions $(0 \%, 30 \%$, and $60 \%)$. The number of small drops increases with increasing ceramic volume fraction while the number of intermediate drops decreases. This is probably related to the strain heterogeneity induced by the second phase. 
The same effect is observed in the simulations of the present work, conducted for much higher particle volume fractions. The statistical stress drop analysis carried out on the tensile curve for the $0 \%, 30 \%$, and $60 \%$ volume fraction simulations is given in Figure 8. Even if a proportion of small drops (below $0.5 \mathrm{MPa}$ ) exists for all three simulations, this proportion is much larger for the simulation with a large volume fraction of particles. On the contrary, the proportion of intermediate drops (between 1 and $3 \mathrm{MPa}$ ) is larger in the case of the matrix material ( $0 \%$ of volume fraction). The proportion of large drops (above $3 \mathrm{MPa}$ ) is not very significant in our analysis since they are related to the rebound of the bands at the ends of the sample as observed on Figure 4. The reason for the larger number of small drops in the presence of a second phase is very probably related to the strain heterogeneity induced by the latter in comparison with a more homogeneous material [21], and to the fact that the particles do, on a microscale, interfere with the propagation of deformation bands. The rather random propagation of the band observed on Figure 4 for the $60 \%$ simulation is in agreement with this assumption compared with the very smooth propagation that is observed inhomogeneous material simulation for the A-type bands [15]. Note however that, at the macroscale, this does not prevent the formation of relatively smooth bands across the composites, see Figure 1.

\section{Conclusion}

The main findings of the present work can be summarised as follows:

(i) To explain initial experimental observations, the Portevin-Le Chatelier effect has been simulated during tensile loading of a $\mathrm{AlCu} / \mathrm{Al}_{2} \mathrm{O}_{3}$ metal matrix composite with a large volume fraction of ceramic particles (60\%).

(ii) The serrations on the stress/strain curves and the propagation of bands of localised plasticity can be reproduced by $2 \mathrm{D}$ finite element simulations using a strain ageing elasto-visco-plastic model for the matrix associated with a two-phase mesh based on the real micro-structure.

(iii) The ceramic particles act as obstacles to band propagation; consequently, the latter is more disordered and random than for the pure matrix material; however, a major result of the work is that, even for this very large volume fraction of particles, the band globally forms and propagates forward across the whole volume, as it does in homogeneous non reinforced alloys.

(iv) The serration shape is also affected by the introduction of the second phase; namely the strain heterogeneity induced by the particles increases the number of small stress drops observed on the stress/strain curves.

(v) The statistics of stress drops predicted by the model is in accordance with the same analysis performed on experimental results in [21]. 


\section{Acknowledgments}

A. Mortensen wishes to acknowledge the support of the ++ Swiss National Science Foundation, Project No. 200020-107556, and the contributions of Mr F. Juvet and Dr R. Müller, in producing and discussing the pictures in Figure 1.

\section{Disclosure statement}

No potential conflict of interest was reported by the author(s).

\section{References}

[1] A. Le Chatelier, Influence du temps et de la température sur les essais au choc, Rev. Métall.6 (1909), pp. 914-917.

[2] A. Cottrell and B. Bilby, Dislocation theory of yielding and strain ageing of Iron, Proc. Phys. Soc. A62 (1949), pp. 49-62.

[3] A. Portevin and F. Le Chatelier, Sur le phénomène observé lors de l'essai de traction d'alliages en cours de transformation, Comp. Rend. l'Acad. Sci. 176 (1923), pp. 507-510.

[4] R. De Codes and A. Benallal, Influence of specimen geometry on the Portevin-Le Chatelier effect due to dynamic strain aging for the AA5083-h116 aluminum alloy, J. Mech. Mater. Struct. 6 (2011), pp. 951-968, 11th Pan-American Congress of Applied Mechanics (PACAM)/48th Meeting of the Society-for-Natural-Philosophy (SNP), Foz do Iguacu, BRAZIL, JAN 04-08, 2010.

[5] J. Coer, P. Manach, H. Laurent, M. Oliveira, and L. Menezes, Piobert-Lüders plateau and Portevin-Le Chatelier effect in an Al-Mg alloy in simple shear, Mech. Res. Commun. 48 (2013), pp. 1-7.

[6] D. Delpueyo, X. Balandraud, and M. Grédiac, Calorimetric signature of the Portevin-Le Chatelier effect in an aluminum alloy from infrared thermography measurements and heat source reconstruction, Mater. Sci. Eng.: A 651 (2016), pp. 135-145. Available at http://www.sciencedirect.com/science/article/pii/S0921509315305153.

[7] S.C. Ren, G. Rousselier, T. Morgeneyer, M. Maziére, and S. Forest, Numerical investigation of dynamic strain ageing and slant ductile fracture in a notched specimen and comparison with synchrotron tomography 3D-DVC, Proc. Struct. Integr. 2 (2016), pp. 3385-3392.

[8] T. Böhlke, G. Bondar, Y. Estrin, and M. Lebyodkin, Geometrically non-linear modeling of the Portevin-Le Chatelier effect, Comput. Mater. Sci. 44 (2009), pp. 1076-1088.

[9] S. Gupta, A.J. Beaudoin, Jr., and J. Chevy, Strain rate jump induced negative strain rate sensitivity (NSRS) in aluminum alloy 2024: Experiments and constitutive modeling, Mater. Sci. Eng.: A 683 (2017), pp. 143-152. Available at//www.sciencedirect.com/ science/article/pii/S0921509316314927.

[10] S.C. Ren, T.F. Morgeneyer, M. Mazière, S. Forest, and G. Rousselier, Portevin-Le Chatelier effect triggered by complex loading paths in an Al-Cu aluminium alloy, Phil. Mag. 99 (2019), pp. 659-678.

[11] B. Reyne, P.Y. Manach, and N. Moës, Macroscopic consequences of Piobert-Lüders and Portevin-Le Chatelier bands during tensile deformation in Al-Mg alloys, Mater. Sci. Eng.: A 746 (2019), pp. 187-196.

[12] H. Dierke, F. Krawehl, S. Graff, S. Forest, J. Sach, and H. Neuhäuser, Portevin-Le Chatelier effect in Al-Mg alloys: Influence of obstacles - experiments and modelling, Comput. Mater. Sci. 39 (2007), pp. 106-112. 
[13] S. Graff, H. Dierke, S. Forest, H. Neuhäuser, and J.L. Strudel, Finite element simulations of the Portevin-Le Chatelier effect in metal-matrix composites, Phil. Mag. 88 (2008), pp. 3389-3414.

[14] A. Benallal, T. Berstad, T. Borvik, O. Hopperstad, I. Koutiri, and R. Nogueira de Codes, An experimental and numerical investigation of AA5083 aluminium alloy in presence of the Portevin-Le Chatelier effect, Int. J. Plast. 24 (2008), pp. 1916-1945.

[15] M. Mazière and H. Dierke, Investigations on the Portevin-Le Chatelier critical strain in an aluminum alloy, Comput. Mater. Sci. 52 (2012), pp. 68-72.

[16] R. Schwarz and L. Funk, Kinetics of the Portevin-Le Chatelier effect in Al 6061 alloy, Acta Metall. 33 (1985), pp. 295-307. Available at http://www.sciencedirect.com/ science/article/pii/0001616085901488.

[17] M. Härtel, C. Illgen, P. Frint, and M.F.X. Wagner, On the PLC effect in a particle reinforced AA2017 alloy, Metals 8 (2018), p. 88.

[18] A. Miserez and A. Mortensen, Fracture of aluminium reinforced with densely packed ceramic particles: Influence of matrix hardening, Acta Mater. 52 (2004), pp. 5331-5345.

[19] A. Miserez, R. Müller, and A. Mortensen, Increasing the strength/toughness combination of high volume fraction particulate metal matrix composites using an $\mathrm{Al}-\mathrm{Ag}$ matrix alloy, Adv. Eng. Mater.8 (2006), pp. 56-62.

[20] Y. Estrin and M. Lebyodkin, The influence of dispersion particles on the Portevin-Le Chatelier effect: From average particle characteristics to particle arrangement, Mater. Sci. Eng. A 387 (2004), pp. 195-198, 13th International Conference on the Strength of Materials (ICSMA 13), Budapest, HUNGARY, AUG, 2003.

[21] M. Lebyodkin and Y. Estrin, Multifractal analysis of the Portevin-Le Chatelier effect: General approach and application to $\mathrm{AlMg}$ and $\mathrm{AlMg} / \mathrm{Al}_{2} \mathrm{O}_{3}$ alloys, Acta Mater. 53 (2005), pp. 3403-3413.

[22] S. Lee, S.J. Lee, S.S. Kumar, K. Lee, and B.C. De Cooman, Localized deformation in multiphase, ultra-fine-grained 6 Pct Mn transformation-induced plasticity steel, Metall. Mater. Trans. A-Phys. Metall. Mater. Sci. 42A (2011), pp. 3638-3651, Symposium on Austenite Formation and Decomposition IV, Houston, TX, Oct 17-21, 2010.

[23] S. Lee and B.C. De Cooman, Annealing temperature dependence of the tensile behavior of 10 pct Mn multi-phase TWIP-TRIP steel, Metall. Mater. Trans. A-Phys. Metall. Mater. Sci. A 45 (2014), pp. 6039-6052.

[24] X. Wang, L. Wang, and M. Huang, Kinematic and thermal characteristics of Lüders and Portevin-Le Chatelier bands in a medium Mn transformation-induced plasticity steel, Acta Mater. 124 (2017), pp. 17-29. Available at//www.sciencedirect.com/science/ article/pii/S1359645416308461.

[25] M. Callahan, A. Perlade, and J.H. Schmitt, Interactions of negative strain rate sensitivity, martensite transformation, and dynamic strain aging in 3 rd generation advanced high-strength steels, Mater. Sci. Eng.: A 754 (2019), pp. 140-151.

[26] Y. Brechet and Y. Estrin, On a pseudo-Portevin-Le Chatelier effect, Scr. Metall. Mater. 31 (1994), pp. 185-190.

[27] Y. Brechet and Y. Estrin, On the influence of precipitation on the Portevin-Le Chatelier effect, Acta Metall. Mater. 43 (1995), pp. 955-963.

[28] D. Thevenet, M. Mliha-Touati, and A. Zeghloul, The effect of precipitation on the Portevin-Le Chatelier effect in an Al-Zn-Mg-Cu alloy, Mater. Sci. Eng. A-Struct. Mater. Prop. Microstruct. Process. 266 (1999), pp. 175-182.

[29] D. Thevenet, M. Mliha-Touati, and A. Zeghloul, Characteristics of the propagating deformation bands associated with the Portevin-Le Chatelier effect in an Al- $\mathrm{Zn}-\mathrm{Mg}-$ $\mathrm{Cu}$ alloy, Mater. Sci. Eng. A-Struct. Mater. Prop. Microstruct. Process. 291 (2000), pp. 110-117. 
[30] L.P. Kubin and Y. Estrin, The Portevin-Le Chatelier effect in deformation with constant stress rate, Acta Metall. 33 (1985), pp. 397-407.

[31] P. McCormick, Theory of flow localization due to dynamic strain ageing, Acta Metall. 36 (1988), pp. 3061-3067.

[32] M. Maziére, J. Besson, S. Forest, B. Tanguy, H. Chalons, and F. Vogel, Numerical aspects in the finite element simulation of the Portevin-Le Chatelier effect, Comput. Meth. Appl. Mech. Eng. 199 (2010), pp. 734-754.

[33] R.H. Song, H.L. Qin, Z.N. Bi, J. Zhang, H. Chi, E. Busso, and D.F. Li, Experimental and numerical investigations of dynamic strain ageing behaviour in solid solution treated Inconel 718 superalloy, Eng. Comput., preprint (2020).

[34] B. Klusemann, G. Fischer, T. Boehlke, and B. Svendsen, Thermomechanical characterization of Portevin-Le Chatelier bands in AlMg $g_{3}$ (AA5754) and modeling based on a modified Estrin-McCormick approach, Int. J. Plast. 67 (2015), pp. 192-216.

[35] L. Mansouri, J. Coër, S. Thuillier, H. Laurent, and P.Y. Manach, Investigation of Portevin-Le Chatelier effect during Erichsen test, Int. J. Mater. Form. 13 (2020), pp. 687-697.

[36] M. Marchenko, M. Mazière, S. Forest, and J.L. Strudel, Crystal plasticity simulation of strain aging phenomena in alpha-titanium at room temperature, Int. J. Plast. 85 (2016), pp. 1-33.

[37] S. Gupta, V. Taupin, C. Fressengeas, and J. Chevy, Crystal plasticity modeling of the effects of crystal orientation and grain-to-grain interactions on DSA-induced strain localization in Al-Li alloys, Materialia 8 (2019), pp. 100467.

[38] H. Ovri, D. Steglich, H. Dieringa, and E.T. Lilleodden, Grain-scale investigation of the anisotropy of Portevin-Le Chatelier effect in Mg AZ91 alloy, Mater. Sci. Eng. A 740-741 (2019), pp. 226-234.

[39] A. Miserez, R. Müller, A. Rossoll, L. Weber, and A. Mortensen, Particle reinforced metals of high ceramic content, Mater. Sci. Eng. A-Struct. Mater. Prop. Microstruct. Process. 387 (2004), pp. 822-831.

[40] A. Miserez, A. Rossoll, and A. Mortensen, Fracture of aluminium reinforced with densely packed ceramic particles: Link between the local and the total work of fracture, Acta Mater. 52 (2004), pp. 1337-1351.

[41] A. Miserez, A. Rossoll, and A. Mortensen, Investigation of crack-tip plasticity in high volume fraction particulate metal matrix composites, Eng. Fract. Mech. 71 (2004), pp. 2385-2406.

[42] M. Kouzeli and A. Mortensen, Size dependent strengthening in particle reinforced aluminium, Acta Mater. 50 (2002), pp. 39-51.

[43] A. Mortensen, M. Kouzeli, L. Weber, and C.S. Marchi, Corrigendum to: On the tensile behaviour of infiltrated alumina particle reinforced aluminium composites, Acta Mater. 51 (2003), pp. 6493-6496.

[44] T. Richeton, G.F. Wang, and C. Fressengeas, Continuity constraints at interfaces and their consequences on the work hardening of metal-matrix composites, J. Mech. Phys. Solids 59 (2011), pp. 2023-2043.

[45] A. Mortensen and J. Llorca, Metal matrix composites, Ann. Rev. 40 (2010), pp. 243-270.

[46] S. Puri, A. Das, and A. Acharya, Mechanical response of multicrystalline thin films in mesoscale field dislocation mechanics, J. Mech. Phys. Solids 59 (2011), pp. 2400-2417.

[47] S. Zhang, P. McCormick, and Y. Estrin, The morphology of Portevin-Le Chatelier bands: Finite element simulation for Al-Mg-Si, Acta Mater. 49 (2001), pp. 1087-1094.

[48] S. Graff, S. Forest, J.L. Strudel, C. Prioul, P. Pilvin, and J.L. Béchade, Strain localization phenomena associated with static and dynamic strain ageing in notched specimen: Experiments and finite element simulations, Mater. Sci. Eng. A 387 (2004), pp. 181-185. 
[49] A. Marchenko, M. Mazière, S. Forest, and J.L. Strudel, Crystal plasticity simulation of strain aging phenomena in alpha-titanium at room temperature, Int. J. Plast. 85 (2016), pp. 1-33.

[50] J. Besson and R. Foerch, Large scale object-oriented finite element code design, Comput. Meth. Appl. Mech. Eng. 142 (1997), pp. 165-187.

[51] Z-set package, Non-linear material \& structure analysis suite, preprint (2013). Available at www.zset-software.com.

[52] H. Ait-Amokhtar, S. Boudrahem, and C. Fressengeas, Spatiotemporal aspects of jerky flow in Al-Mgalloys, in relation with the Mg content, Scr. Mater. 54 (2006), pp. 21132118.

[53] H. Ait-Amokhtar, C. Fressengeas, and S. Boudrahem, The dynamics of Portevin-Le Chatelier bands in an Al-Mg alloy from infrared thermography, Mater. Sci. Eng. A 488 (2008), pp. 540-546.

[54] J. Besson, G. Cailletaud, J.L. Chaboche, S. Forest, and M. Blétry, Non-Linear Mechanics of Materials, Solid Mechanics and its Applications 167, Springer-Verlag, Berlin, Heidelberg, 2009. 